\title{
AUTOAVALIAÇÃO INSTITUCIONAL E (IN)CULTURA DE PARTICIPAÇÃO NA UNIVERSIDADE
}

\author{
G. T. FÉLIX e D. B. V. FURTADO \\ Universidade Federal de Santa Maria \\ gladesfelix@hotmail.com*
}

Artigo submetido em maio/2014 e aceito em janeiro/2016

DOI: 10.15628/holos.2016.2151

\section{RESUMO}

Este artigo tem por objetivo apresentar uma discussão recorrente no âmbito das políticas públicas: a relação entre avaliação interna: autoavaliação no contexto do Sistema Nacional de Avaliação da Educação Superior (Sinaes) e a intensidade de participação da comunidade universitária. Tal estudo se fundamenta na análise de uma série histórica de quatro anos (2008, 2009, 2010 e 2012) da autoavaliação institucional implementada numa universidade pública. De primeiro, apresenta-se o conceito de participação na visão de alguns teóricos; na sequência, seguem-se os caminhos percorridos a partir das informações coletadas, quando se descreve o panorama do processo e da participação institucional, com base na pesquisa bibliográfica e documental. $\mathrm{Na}$ perspectiva de atribuir-lhes alguma significação, por último, são descritos os resultados da participação e relacionados com o discurso de alguns autores. Concluise que no período investigado predomina, institucionalmente, a participação de baixa intensidade, que se consubstancia na falta de melhorias, constituindose, assim, num desafio para a governança universitária. Para minimizar a problemática, sugerem-se medidas de curto, médio e longo prazos, em favor de uma cultura permanente de avaliação na universidade.

PALAVRAS-CHAVE: Autoavaliação, avaliação, participação, universidade.

\section{INSTITUTIONAL SELF-ASSESSMENT AND (IN)CULTURE OF PARTICIPATION IN UNIVERSITY}

\begin{abstract}
This article aims to present a recurring discussion in public policy: the relationship between internal evaluation: self-assessment in the context of SINAES and intensity of participation of the university community. This study is based on analysis of a historical series of four years (2008, 2009, 2010 and 2012) of institutional selfassessment implemented in a public university. First, we present the concept of participation in the view of some theorists, subsequent follow up the paths taken from the information collected, when describing the process landscape and institutional participation, based on the
\end{abstract}

literature and documents. In the approach of giving it some meaning, finally, describes the results of participation and relates to the speech of some authors. We conclude that in the investigated period predominates, institutionally, the participation of low intensity that is embodied in the lack of improvement, thus constituting, a challenge for university governance. To minimize the problem are suggested actions in the short, medium and long term, in favor of a permanent evaluation culture at the university.

KEYWORDS: Self-assessment, evaluation, participation, university 


\section{INTRODUÇÃO}

Este artigo analisa a intensidade da participação da comunidade universitária no processo de avaliação interna: autoavaliação, numa dada série histórica de uma instituição federal de ensino superior no contexto de aperfeiçoamento do Sistema Nacional de Avaliação da Educação Superior (Sinaes), criado pela Lei no 10.861/2004. Por essa normativa, o pilar da avaliação regulatória temse desenvolvido estreitamente vinculado ao progressivo aviltamento das políticas sociais e públicas e particularmente ao processo gradual de deterioração dos orçamentos das universidades brasileiras.

No caso brasileiro, há uma crise nas instituições públicas de educação, gerada na relação delas com o Estado, em que se acrescentam as dificuldades cada vez maiores e mais complexas do setor produtivo em particular e de toda a nova ordem econômica em geral. Por isso, não é difícil compreender que a educação superior é um dos campos cujo domínio é objeto da mais acirrada disputa política. Por tais razões, podemos perceber por que a avaliação regulatória passou a ter clara centralidade nas políticas de reforma da educação e da sociedade.

Integrante desse sistema, a instituição estudada, ao longo do tempo, segue a política estatal de avaliação, cumprindo os processos e os fluxos de atendimento às dimensões do Sinaes, prioritariamente para fins de credenciamento institucional, conforme exigências de supervisão e controle do Estado. Também, permite que a Instituição de Ensino Superior (IES) conheça-se e faça a sua autocrítica, por meio de seu desempenho nas diversas atividades oferecidas à comunidade interna e externa.

Não pretendemos esgotar as questões atinentes à autoavaliação, pois isso é muito peculiar e diz respeito a cada perfil institucional, mas, tão somente, discutir pontos implicativos do desafio da participação para a consolidação de uma cultura avaliativa na universidade. Portanto, especificamente objetivamos delinear a intensidade da participação da comunidade universitária em sucessivos processos autoavaliativos em comparativo com as melhorias e o aperfeiçoamento advindos desses processos.

$\mathrm{O}$ artigo se traduz num esforço de compreender as questões atinentes à participação na autoavaliação e está organizado em quatro partes: o que é participação, quais os caminhos do processo, qual o panorama da participação institucional e quais as perspectivas para a participação.

\section{DESCREVENDO O QUE É PARTICIPAÇÃO}

A participação é um elemento inerente à democracia e existe desde os primórdios do povo grego, no Período Clássico, chegando à democracia representativa moderna, até a discussão das diferentes correntes da teoria democrática contemporânea.

Para Toro e Werneck (2004), a democracia é uma forma de construir a liberdade e a autonomia da sociedade, aceitando como seu fundamento a diversidade e a diferença. Sendo assim, a democracia está relacionada à ideia da participação de toda a sociedade em construir e viver uma ordem social em que os direitos, a justiça e dignidade sejam possíveis para todos. 
A prática da democracia direta (participação forte) que caracterizou as cidades da Antiga Grécia teve suas origens na democracia clássica em que as decisões sobre pequenas e grandes questões seriam tomadas pelo sistema direto e plebiscitário, portanto não era aceita a representação, mas a totalidade dos cidadãos é que deveriam decidir. Atenas se enaltecia, pois julgava ter uma democracia que alternava a isonomia, (igualdade de direitos perante a lei), a isegoria (igualdade e franqueza no falar) e a isocracia (igualdade no poder). (LEITE, 2005, p. 24, grifos da autora).

Ao longo dos tempos, a democracia direta e participativa demonstrou relevante esforço mental e racional na sua implementação e caracterização, pois desde Rousseau, Marx e Engels essas ideias vêm sendo reelaboradas.

Com o avanço das transformações sociais, políticas, culturais e econômicas ao longo do tempo, a questão da participação tem sido ressignificada, tendo adquirido diversas configurações e dimensões. Isso levou ao surgimento de muitos significados e conceitos, no entanto é importante refletirmos a partir da contribuição de teóricos que deram concretude a paradigmas que modificaram o pensamento e as relações sociais.

Para Leite (2005), espaços de participação são sempre espaços de conflito e jogos de interesse e poder, portanto, para realizarem-se estudos que tratam dessa temática, cabe articular as teorias recentes aos pressupostos clássicos advindos do século XVIII, ou seja, os estudos de Rousseau (1978), Marx e Engels (1980), Demo (2001), Barber (1997), Ammann (1997), Bordenave (1994), Pateman (1974), Macbeth (1984) e Gadotti (1995).

Rousseau (1978) acreditava que a participação assegurava a igualdade política e caracterizava-se por ser educativa, uma vez que evidenciava a possibilidade de desenvolver uma atuação responsável, particular, social e política, visto que cada cidadão passava não apenas os seus interesses individuais. Nesse modelo de participação, seria necessário que as associações de cunho deliberativo defendessem o bem comum e estivessem amplamente informadas, para garantir que os objetivos fossem alcançados.

Marx e Engels renovaram a dialética mencionada por Heráclito na Antiga Grécia quando disseram que as coisas estavam em constante movimento. Por isso, "[...] não é a consciência que determina a vida, mas sim a vida que determina a consciência” (MARX; ENGELS, 1980, p. 26).

Esses autores rejeitaram a supremacia de uma classe sobre a outra, pois entendiam que a defesa de interesses particulares desconsiderava os interesses coletivos. Frente a isso, fizeram profundas críticas à classe burguesa, que explorava a classe trabalhadora intensificando a divisão do trabalho, que isola e desintegra os trabalhadores. Só com muita luta seria possível vencer os indivíduos isolados.

Para Demo (2001), a participação é conquista, pois é um processo infindável, em constante vir a ser, sempre se fazendo: “[...] é autopromoção e existe enquanto conquista processual. Não existe participação suficiente, nem acabada, a participação não pode ser entendida como dádiva, concessão ou como algo preexistente" (DEMO, 2001, p. 18). Podemos afirmar, então, que é pela participação que se constitui a mudança do próprio ser, é na integração que existe a possibilidade de mudar ou de se permitir a estabilização do que está posto, tornando-se um elemento de poder. 
Barber (1997) reconhece ser a participação parte do regime da democracia direta, expressando-se através da participação cujo valor principal, em relação a outras formas, corresponderia à atividade de um tipo de cidadania centralizada em um governo descentralizado.

A democracia forte é uma política de participação onde o conflito é resolvido, na ausência de toda racionalidade extrínseca, graças a uma auto legislação contínua, uma participação constante e graças à criação de uma comunidade política capaz de transformar os indivíduos privados e independentes em cidadãos livres, tanto quanto os interesses privados, parciais, em bem comum. (BARBER, 1997, p. 171).

$\mathrm{Na}$ ideia de Leite (2005), a democracia participativa ou forte seria o instrumento epistemológico de um pensamento e de uma ação política no espaço público. Frente a isso, Barber (1997) apresenta um modelo conceitual que distingue democracia forte de outras formas (fracas), quando a ênfase está na polarização entre a democracia direta de dois tipos - unitária ou forte e a democracia representativa do tipo autoritária, jurídica e pluralista.

Numa democracia forte, o cidadão e o povo se confundem; se é cidadão na medida da participação política na coisa pública, deliberando em assembleias, agindo, partilhando, contribuindo para o bem comum da cidade, da região, da comunidade, associação, fábrica, movimento social, sindicato e universidade. (LEITE, 2005, p. 76).

Segundo Bordenave (1994), é a participação que garante a democracia, porque facilita o crescimento da consciência crítica e seu poder de reivindicação, preparando a população para adquirir mais poder na sociedade. Porém, participar ou não é uma decisão de cada um, isso depende de as pessoas se sentirem responsáveis por provocar e construir mudanças. Esse pensamento dialoga diretamente com que aponta Guerra (2002), o qual nos esclarece que a participação torna-se um princípio básico da democracia quando permite estabelecer o debate aberto e a capacidade de crítica efetiva, de modo que possibilitará gerar os avanços necessários para a transformação das estruturas.

Ammann (1997) segue a ideia de que a vivência e a intensidade do ato de participar são indissociáveis do contexto histórico de determinada sociedade, por isso constituem um processo global, integrado por vários elementos articulados e interdependentes que, separados, não podem ser denominados de participação. A participação não pode ser medida pelo desempenho ativo ou passivo, mas pela intensidade e qualidade da participação.

Para Gadotti (1995), a participação é um ponto crucial, por isso é importante fortalecermos a gestão compartilhando ações, pois a interação entre participantes não é só estar juntos, trocar ou dividir ideias e tarefas, mas também enfrentar dificuldades e superar divergências. Dessa forma, na gestão compartilhada, conforme aponta Guerra (2002), a transformação real nas ações se dará na efetiva escuta atenta de todos no processo, sem discriminar ou hierarquizar a participação.

Em se tratando de intensidade da participação, Bordenave (1994), por exemplo, apresentanos um modelo de grau de participação, com sete tipos, que parte da menor para a maior complexidade e controle, ou seja, informação - quando os dirigentes informam aos membros da organização as decisões já tomadas; consulta facultativa - quando a administração, se quiser e quando quiser, pode consultar os subordinados, solicitando sugestões; consulta obrigatória - os subordinados são consultados em determinadas situações, embora a decisão final seja dos 
superiores; elaboração - quando os subordinados elaboram propostas e recomendam medidas que a administração aceita ou rejeita mediante justificativa; cogestão - quando a administração é compartilhada por um colegiado; delegação - quando os administrados têm autonomia em certos campos, de acordo com as regras antes definidas em consenso; autogestão - quando o grupo define seus objetivos, escolhe os meios, estabelece os controles necessários e a liderança é compartilhada.

Já Pateman (1974) distingue três tipos de participação, baseados na crítica de Habermas aos mecanismos de legitimação do Estado moderno, quais sejam, participação plena, em que se partilha o poder real e individual; participação parcial, quando se pode influir nas decisões, mas não tomá-las ou participar delas; e pseudoparticipação, quando as questões de que se participa foram decididas previamente, real ou formalmente.

Macbeth (1984) faz uma diferenciação entre três formas de participar: decidir - supõe exercer o poder; controlar - é ter responsabilidade sobre a forma como o outro o exerce; e comunicar - consiste na explicação dada por quem exerce o poder.

A partir do jogo de ideias desenvolvidas, podemos perceber a importância do ato de participar, pois, como Guerra (2002) defende cada pessoa torna-se responsável por participar, não se constituindo, assim, como um direito, mas como um dever. É imprescindível que todos contribuam com iniciativa e decisão, não devendo, dessa forma, renunciar à participação, e sim empenhar-se na busca de melhorias no processo do qual estão convidados a fazer parte.

Na sequência, passamos a descrever informações relativas ao objeto da pesquisa.

\section{DESCREVENDO OS CAMINHOS DO PROCESSO}

Esta investigação constitui-se num estudo de caso de natureza quantitativa e qualitativa, caracterizada como descritiva (YIN, 2001), com base na observação participada e na pesquisa bibliográfica, qualiquantitativa e documental.

Ressaltamos que a preferência pelo caso se deu pela proximidade e completude do material, visto ser o ambiente profissional dos investigadores que acompanham, há alguns anos, o andamento de tais processos na IES em questão. A problemática chama a atenção pela alternância entre estagnação e decadência, mas sempre ineficiência.

Evidenciamos a importância de se terem realizado o acompanhamento e o subsequente compilamento dos dados quantitativos da participação, divulgados pelo Centro de Processamento de Dados (CPD) da instituição, ao final de cada processo, por ano (2008, 2009, 2010 e 2012) e por segmento (alunos da graduação, alunos da pós-graduação, docentes, gestores, técnicoadministrativos e egressos), o que nos possibilitou a sistematização de uma série histórica comparativa, que desvelou a dimensão do problema.

O levantamento dos dados e o modo de realização da pesquisa pela instituição, nos quatro anos, foram iguais, ou seja, houve a aplicação de um questionário on-line específico por segmento, com questões fechadas, induzindo uma resposta, com até cinco variáveis de escolha. Os instrumentos foram elaborados e implementados pela Comissão Própria de Avaliação (CPA), com base nas dez dimensões do Sinaes, contendo entre 28 e 54 questões, além de um espaço para sugestões, recomendações ou críticas. A consulta era voluntária e ocorreu nos finais de semestres, 
entre dezembro e janeiro de cada ano, com prazo determinado, quando os respondentes acessavam o instrumento no sítio institucional, em um link específico, por meio de uma senha pessoal.

Em vista disso, as seis Comissões Setoriais de Avaliação do campus central e as três de unidades descentralizadas tiveram a incumbência de implementar nas respectivas unidades as determinações oriundas da CPA, tendo relativa autonomia apenas para o processo de sensibilização entre seus pares.

Os resultados quantitativos parciais da participação dos diferentes segmentos dos referidos processos eram computados diariamente, durante cada evento, pelo CPD, e enviados via correio eletrônico para as Comissões Setoriais analisarem e intensificarem a sensibilização no sentido de chamar a comunidade para a participação, haja vista que, por parte da CPA, nunca houve uma prévia sensibilização, responsabilizando, assim, cada setorial, sem fornecer os recursos financeiros, humanos e técnicos necessários para que atingissem o objetivo de mobilização para a participação.

Os resultados finais da autoavaliação eram divulgados pela CPA para todas as setoriais, que, antes disso e ao final do processo, tiveram um tempo para organizar seus relatórios finais, com base num modelo padrão, os quais são parte integrante do Relatório Final do processo de autoavaliação da instituição, que é enviado para o Instituto Nacional de Estudos e Pesquisas Educacionais Anísio Teixeira/Ministério da Educação (Inep/MEC), diante das exigências de controle e supervisão do Sinaes, para fins de credenciamento institucional, bem como prestação de contas dos serviços oferecidos à comunidade e região pela IES.

Com base nisso, será implementado o seguinte tratamento para os dados coletados em torno da participação institucional.

1- $\quad$ Com base na pesquisa bibliográfica, descrever o que é participação na visão de alguns teóricos.

2- $\quad$ Com base na pesquisa quantitativa e documental, descrever em percentuais de 0 até $60 \%$ o panorama da participação institucional, por meio de um comparativo na forma de gráfico, considerando a escala de 0 a $70 \%$ para a participação nos respectivos anos, por segmento, distinguindo estes por cores diferentes.

3- $\quad$ Com base na pesquisa quantitativa, descrever e analisar os índices de intensidade da participação por ano, por segmento, da série estudada e da instituição.

4- Descrever e relacionar os resultados ao discurso predominante de alguns teóricos.

A seguir, apresentamos o panorama da participação dos diferentes segmentos nos processos avaliativos implementados pela IES entre 2008, 2009, 2010 e 2012.

\section{DESCREVENDO O PANORAMA DA PARTICIPAÇÃO INSTITUCIONAL}

A qualidade da universidade pode ser compreendida no seu marco institucional e pela visão da comunidade e da sociedade. Leite (2005) defende que a universidade, para atingir patamares mais avançados de qualidade, deve partir de um ponto: a avaliação institucional, que se constitui no diagnóstico ou retrato falado de uma instituição. 
O formato de avaliação da educação superior no âmbito do Sinaes, denominado de Avaliação Institucional, resulta de um amplo processo que utiliza diagnósticos, realizados por meio de diversos procedimentos avaliativos.

Portanto, o Sinaes integra três modalidades principais de instrumentos de avaliação, aplicados em diferentes momentos. O primeiro denomina-se Avaliação das Instituições de Ensino Superior (Avalies) e se desenvolve a partir de dois instrumentos: a) avaliação interna (autoavaliação), sob a responsabilidade das CPAs de cada IES, sendo orientada pelas diretrizes e pelo roteiro da autoavaliação institucional da Comissão Nacional da Avaliação da Educação Superior (Conaes); e b) avaliação externa, realizada por comissões designadas pelo Inep, conforme as diretrizes estabelecidas pela Conaes (CONAES, 2004).

A segunda modalidade é a Avaliação dos Cursos de Graduação (ACG), que avalia os cursos de graduação por meio de instrumentos e procedimentos que incluem visitas in loco por comissões externas. A terceira é a avaliação do desempenho dos estudantes (Enade), que objetiva aferir o rendimento dos alunos dos cursos de graduação em relação aos conteúdos programáticos, suas habilidades e competências.

Frente a essa amplitude e às determinações que são impostas às IES pelo Sinaes, nesta investigação, analisamos os dados concretos da participação da comunidade universitária, relativos ao formato Avalies, no que tange à avaliação interna: autoavaliação institucional de uma IES pública.

O gráfico a seguir apresenta um recorte da participação da comunidade na série investigada. A partir dos dados apresentados, pretendemos revelar, por ano e por segmento, a quantidade de participantes aptos à consulta e os que efetivamente participaram por segmento. Após, analisamos o nível de intensidade dessa participação, tendo por base as teorias de Barber (1997) e Pateman (1974), já mencionados.

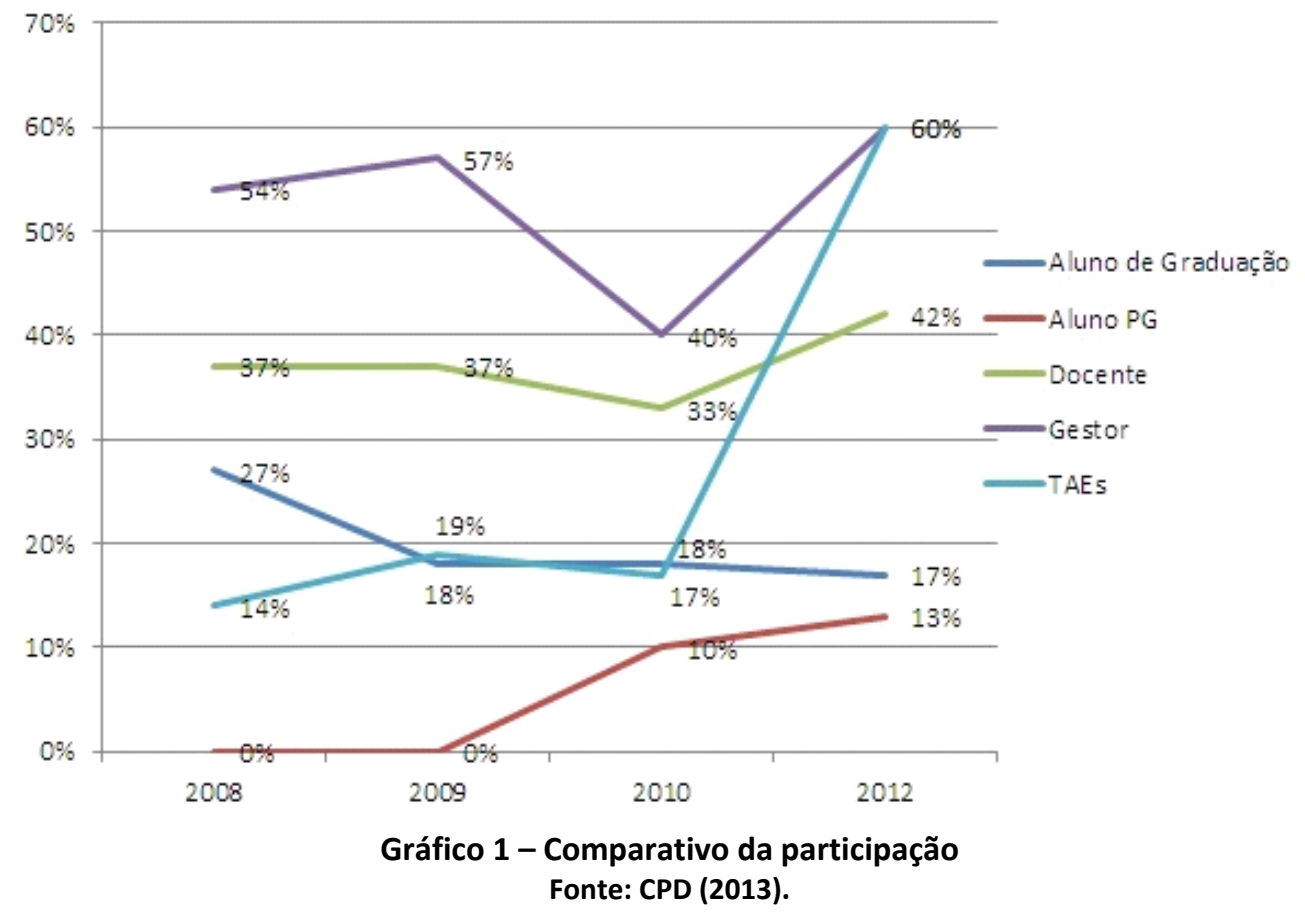

No ano de 2008, a comunidade contava com 17.895 integrantes nos diferentes segmentos, entre estes 4.890 participaram (27\%). Especificamente, na época computava-se o seguinte por 
segmento: alunos da graduação: 13.920, participaram 3.804 (27\%); docentes: 1.187, participaram 638 (37\%); gestores: 638 participaram 348 (54\%); e técnico-administrativos: 2.150, participaram 300 (14\%). Alunos da pós-graduação passaram a participar somente a partir de 2010. Os egressos, apesar de fazerem parte da consulta, obtiveram menos de $1 \%$ de participação, não sendo considerados.

No ano de 2009, a comunidade era composta por 19.894 integrantes, sendo que 4.128 participaram da autoavaliação (21\%). Por segmento, alunos da graduação: 15.857 participaram 2.862 (18\%); docentes: 1.273, participaram 483 (37\%); gestores: 671 participaram 385 (57\%); e técnico-administrativos: 2.093, participaram 398 (19\%).

No ano de 2010, a comunidade era composta por 22.469 integrantes, dos quais 4.211 participaram (19\%). Por segmento, alunos da graduação: 16.974, participaram 3.064 (18\%); alunos da pós-graduação: 2.528, participaram 256 (10\%); docentes: 1.329, participaram 451 (33\%); gestores: 640 participaram 258 (40\%); e técnico-administrativos: 998 participaram 177 (17\%). No ano de 2011, não ocorreu consulta à comunidade, por não ser período de avaliação trienal compulsória segundo o calendário do Inep/MEC para essa instituição.

No ano de 2012, a comunidade era composta por 26.143 integrantes, entre os quais 5.689 participaram (21\%). Por segmento, alunos da graduação: 19.897, participaram 3.506 (17\%); alunos da pós-graduação: 2.847, participaram 376 (13\%); docentes: 1.477, participaram 635 (42\%); gestores: 665 participaram 403 (60\%); e técnico-administrativos: 1.264, participaram 769 (60\%).

Relacionando a participação entre os segmentos, verificamos que, de modo geral, apesar de terem baixa participação, os gestores apresentaram o maior índice de participação na série (52\%). Isso é previsível porque, devido ao cargo que exercem, muitos utilizam esses dados para tomar decisões e planejar políticas de melhoria em suas práticas, além de serem pressionados pelas chefias imediatas a participarem e promoverem entre seus pares o evento institucional.

Os alunos destacaram-se no primeiro ano, já no seguinte mantiveram um percentual muito fraco de participação, encerrando o período com apenas $20 \%$, o que é muito pouco para o tempo e o contingente. Para os docentes, o nível de participação pouco oscilou, contudo o envolvimento é preocupante, porque ainda é de baixo comprometimento frente à importância da função que exercem e aos anos que permanecem na instituição como servidores. De livre e espontânea vontade, compareceram apenas $37 \%$ na série.

Os técnico-administrativos iniciaram com uma participação muito fraca, reagiram no último ano, porém na série investigada alcançaram $27 \%$ de participação. Assim como os demais segmentos, também acusaram um fraco interesse pela autoavaliação. Podemos inferir que, provavelmente, isso tenha sido influenciado pela contagem imprecisa de servidores técnicos por parte dos responsáveis pela autoavaliação, pois, entre 2008 e 2009, notamos que foi levado em conta o total geral de servidores técnicos da instituição e, em 2010 e 2012, separaram-se os servidores técnicos daqueles que estavam no cargo de gestores, sendo estes computados somente nesta categoria.

Assim posta a questão, em termos institucionais, é óbvio que tais resultados refletem uma participação de muito baixa intensidade, representatividade e legitimidade, pois, apesar de ser uma avaliação padronizada, que foi aplicada em quatro anos, atingiu apenas $22 \%$ de participação no período histórico. Ficou constatado pela pesquisa que esse problema é recorrente e deve ser 
de conhecimento da governança universitária, visto que integra o processo de credenciamento da instituição em nível de supervisão governamental, portanto, antes de ser enviado ao Inep, o Relatório Final é aprovado pelo Conselho Universitário (Consu) da instituição.

Para qualificar as discussões, com base na legitimação do Estado moderno, relacionamos os resultados da intensidade da participação com os citados aportes conceituais de participação na visão de Barber (1997) e Pateman (1974).

Com Barber (1997), emerge o esquema da democracia direta +++ e da democracia representativa, frente ao que podemos afirmar que, em nossos achados, há uma clara contradição quanto aos princípios da democracia direta, que é a alavanca da democracia forte e participativa, a qual propugna pela formação de uma comunidade política, de auto legislação e participação constante. Porém, há uma afirmação com os aspectos da democracia representativa de cunho autoritário (fraca---) desde a origem central do processo regulatório estatal, passando pelo nível institucional, até chegar aos segmentos, o que desvela a falta de valorização da autoavaliação como processo de agente transformador, pois, de acordo com tipo de Estado liberal que impõe formatos avaliativos sem consulta aos interessados, ainda que tenha sido feita com legitimidade, dentro dos princípios da democracia representativa, é uma representação/participação de muito baixa intensidade.

Frente ao esquema de participação plena, parcial e pseudoparticipação de Pateman (1974), entendemos que, para os dois primeiros tipos, os resultados são totalmente incompatíveis, mas de conformidade com o terceiro, pois é uma pseudoparticipação que as IES vivem sob a máscara de avaliação. Isso demonstra o jogo de interesses formatado na própria concepção do Sinaes, quando afirma que as IES devem se autoavaliar a partir de seu modelo, missão e realidade, porém dentro de determinadas diretrizes, condições, dimensões, espaços e tempos, previamente estipulados pelo Estado regulador. Tais condições acabam por constituir uma forma de perda de autonomia das IES, de modo que se conformam com tais pressões e seguem as regras burocráticas impostas. Assim, tornam-se impossibilitadas, pela indisponibilidade de tempo, a realizar outro formato avaliativo que produza, concretamente, mudanças e melhorias nas IES.

\section{PARA NÃO CONCLUIR: OUTRAS PERSPECTIVAS PARA A PARTICIPAÇÃO}

Neste texto, buscamos analisar na série histórica a intensidade da participação da comunidade universitária no processo de autoavaliação numa instituição de ensino superior pública.

Os dados expostos não só retratam a intensidade da participação dos segmentos na autoavaliação, mas também, subjetivamente, dizem muito sobre o interesse, a responsabilidade e o comprometimento com o momento histórico e a função que cada segmento desempenha na IES.

Constatamos que, no triênio 2008, 2009 e 2010, a intensidade da participação para a maioria dos segmentos manteve-se entre $14 \%$ e $20 \%$, enquanto os gestores apresentaram melhor desempenho, entre $40 \%$ e $57 \%$, o que não nos exime de enquadrar o período numa participação institucional de baixa intensidade (BARBER, 1997), visto que o contingente de alunos, docentes e técnicos é substancialmente superior ao dos gestores. Tal dissonância não atende às diretrizes da Conaes (2004) quando recomenda que haja ampla consulta à maioria da comunidade, visando cumprir plenamente o seu ciclo participativo. 
O fato de os gestores terem se destacado no estudo, por si só, não reflete a qualidade do processo, mas comprova apenas que, para o Sinaes, quanto mais o gestor está envolvido com o trabalho burocrático, maior é o seu envolvimento com a avaliação burocrática.

No ano de 2012, a participação dos discentes da graduação e pós-graduação atingiu 17\% e $13 \%$, respectivamente, o que comprova terem esses segmentos o pior desempenho na série, enquanto os docentes tiveram discreta reação (42\%), porém não atingiram a metade dos habilitados. Já os técnicos, juntamente com os gestores, deram um salto positivo, apresentando $60 \%$ de participação no ano, no entanto isso ainda não é considerado como participação forte (BARBER, 1997), apenas revela certa tendenciosidade de alguns segmentos. Sendo processos de adesão voluntária, os segmentos não eram obrigados a participar, porém a adesão, uma vez confirmada, passou a ser formalizada, integrando o cômputo da autoavaliação.

Isso confirma que, na série estudada, a intensidade da participação segundo o quadro conceitual de Barber (1997) é fraca (---), média que se repetiu nos quatro anos. Na catalogação de Pateman (1974), podemos considerar uma avaliação de faz de conta (pseudoavaliação), porque as questões que requerem "participação" foram decididas, previamente, parte pelo Sinaes e parte pela CPA formalmente, sem nenhum tipo de consulta à comunidade, tanto que os resultados não são divulgados nem debatidos, como também não servem de diagnóstico para promover melhorias.

Portanto, assim como é recorrente o tipo de participação, supomos que problemas de ordem técnica há muito conhecidos e não resolvidos também se reproduziram, corroborando para a ineficiência dos sucessivos processos, haja vista as reclamações descritas pelos consultados sobre a inoperância do sistema de informatização, questões mal formuladas ou ambíguas, questionários longos, erros de login e senha para acesso e, principalmente, a falta de sensibilização por parte da CPA, para que haja entendimento e valorização do processo, visto ser a etapa de maior importância em qualquer avaliação que se pretenda transformadora.

Em vista desses e de problemas de ordem política, como a própria concepção de avaliação, a continuidade dos processos regulatórios e emancipatórios que virão se constitui num enorme desafio para a governança universitária, que necessita superar ações burocráticas, viciadas e improvisadas, se quiser, de fato, implantar e consolidar uma cultura de avaliação na instituição.

Com isso, esperamos que a governança universitária ponha-se em condição de marcha investigatória na busca de uma inovação de qualidade para o processo avaliativo, ou seja, a partir desta pesquisa, realizem um estudo mais ampliado em torno da qualidade da participação, servindo de diagnóstico que venha a contribuir para que a instituição possa elaborar seu próprio projeto de autoavaliação, uma vez que, assim, estará escutando as vozes da comunidade e não apenas cumprindo uma consulta para alimentar dados para a supervisão do Estado.

Outro ponto é a CPA assumir seu papel e responsabilizar-se pela etapa da sensibilização e da meta avaliação, portanto preparar as pessoas para uma participação efetiva e responsável, de modo permanente e inovador. Mostra-se necessário, após cada consulta, informar e debater com a comunidade os pontos fracos e fortes, propondo mudanças, além de habituarem-se a avaliar a avaliação para melhorar o que ainda não está bom e aperfeiçoar os pontos positivos dos fluxos do processo. 
Em (in)conclusão, reafirmamos a necessidade e a importância de outras perspectivas políticas, culturais e pedagógicas, capazes de levar a uma mudança gradual todo o mecanismo de gestão da avaliação em nível institucional. Isso só será possível com base em ações de curto, médio e longo prazos, obviamente a partir de investimentos financeiros, humanos, técnicos, políticos e investigativos, sem o que não se conseguirá sair das amarras do sistema instituído.

\section{REFERÊNCIAS}

1. AMMANN, B. S. Participação social. São Paulo: Cortez e Moraes, 1997.

2. BARBER, M. Democracia forte. Paris: Desclée de Brouwer, 1997.

3. BORDENAVE, J. E. D. O que é participação? São Paulo: Brasiliense, 1994.

4. BRASIL. Congresso Nacional. Lei no 10.891/2004, de 04 de abril de 2004. Institui o Sistema Nacional de Avaliação da Educação Superior e dá outras providências. Diário Oficial da União, Brasília. DF. 2004.

5. CONAES. Diretrizes para autoavaliação das instituições de ensino superior. 2004. Disponível em: <http://download.inep.gov.br/download/superior/sinaes/orientacoes_sinaes.pdf $>$. Acesso em: 12 dez. 2013.

6. DEMO, P. Participação é conquista: noções de política participativa. São Paulo: Cortez, 2001.

7. GADOTTI, M. Pensamento pedagógico brasileiro. 6. ed. São Paulo: Ática, 1995.

8. GUERRA, M. A. S. Os desafios da participação: desenvolver a democracia na escola. Portugal: Porto Editora, 2002.

9. LEITE, D. Reformas universitárias: avaliação institucional participativa. Petrópolis, RJ: Vozes, 2005.

10. MACBETH, A. The child between: a repport on school-family relations in the countries of European Community. Brussels: Office for Official Publications of the European Communities, 1984.

11. MARX, K.; ENGELS, F. A ideologia alemã (Feuerbach). São Paulo: Hucitec, 1980.

12. PATEMAN, C. Participação e Teoria Democrática. Rio de Janeiro: Paz e Terra, 1974.

13. ROUSSEAU, J. J. O Contrato Social. São Paulo: Formar, 1978.

14. TORO, A. J. B.; WERNECK, N. M. D. Mobilização social: um modo de construir uma democracia e participação. Belo Horizonte: Autêntica, 2004.

15. UFSM. Pró-Reitoria de Administração. Centro de Processamento de Dados (CPD). Relatórios parciais da Avaliação Interna: autoavaliação. Santa Maria, 2013.

16. _. Pró-Reitoria de Planejamento. Comissão Própria de Avaliação (CPA). Relatório Final. Avaliação Interna: autoavaliação. Santa Maria, 2008.

17. _. Pró-Reitoria de Planejamento. Comissão Própria de Avaliação (CPA). Relatório Final. Avaliação Interna: autoavaliação. Santa Maria, 2009.

18. _ Pró-Reitoria de Planejamento. Comissão Própria de Avaliação (CPA). Relatório Final. Avaliação Interna: autoavaliação. Santa Maria, 2010. 
19. _ Pró-Reitoria de Planejamento. Comissão Própria de Avaliação (CPA). Relatório Final. Avaliação Interna: autoavaliação. Santa Maria, 2012.

20. YIN, R. K. Estudo de caso: planejamento e métodos. 2. ed. Porto Alegre: Bookman, 2001. 